\title{
Perceptions about quality of life in a school-based population of adolescents with menorrhagia: implications for adolescents with bleeding disorders
}

\author{
A. PAWAR, * R. KRISHNAN, $\dagger$ K. DAVIS, $\ddagger$ K. BOSMA $\mathbb{S}$ and R. KULKARNI \\ *Pediatric Hematology/Oncology, University of Michigan, Ann Arbor MI, USA; $\dagger$ Eli Broad College of Business, Michigan \\ State University, East Lansing MI, USA; $₫$ Retired School Nurse, Lansing School District. Lansing MI, USA; $\$$ Department \\ of Pediatrics and Human Development, MSU Center for Bleeding and Clotting Disorders, Michigan State University, East \\ Lansing MI, USA
}

Summary. This study examined the effect of menor-
rhagia on the quality of life (QOL) of adolescents. We
used data from a survey of 45 adolescents. Using the
Pictorial Blood Assessment Chart (PBAC) and
a PBAC score of $\geq 100$ we identified adolescents
likely to have menorrhagia. Our statistical analysis indicated that menorrhagia adversely affects the QOL of adolescents. In this article we discuss the implications of our study and future research avenues.

Keywords: adolescents, bleeding disorders, menorrhagia, quality of life, surveys

\section{Introduction}

Menorrhagia, characterized by excessively heavy or prolonged menstrual blood loss of $\geq 80 \mathrm{~mL}$ of blood per cycle, is a common complaint among adult women and can also affect adolescents [1,2]. About $10-15 \%$ of women experience menorrhagia during their lifetime [2]. There are several causes of menorrhagia such as anatomic gynaecological pathology, hormonal imbalances and medical conditions such as hypothyroidism. Acquired and congenital disorders of haemostasis are a common cause of menorrhagia in adolescents [3]. Such disorders include, thrombocytopenia and inherited bleeding disorders, such as von Willebrand Disease, platelet function defects etc. [3-8]; as many as $20 \%$ of women with menorrhagia may have a bleeding disorder [9].

In addition to physiological symptoms such as menstrual pain and heavy bleeding, menorrhagia has been shown to negatively impact quality of life

Correspondence: Roshni Kulkarni, Professor, B 220 Clinical Center, Department of Pediatrics and Human Development, East Lansing, Michigan 48824, USA.

Tel.: 517-355-5039; fax: 517-355-8312;

e-mail: roshni.kulkarni@hc.msu.edu

Accepted after revision 3 January 2008
(QOL) in adults [6,10-12]. Menorrhagia affects a sizeable segment of the female population [2] and often, a significant time elapses (16 years on average) before diagnosis of an underlying bleeding disorder is made $[4,13]$. Jayasinghe et al., examined the prevalence of bleeding disorders in adolescents with menorrhagia [14], however, to the best of our knowledge, the impact of menorrhagia on the QOL of adolescents has not been explored. To determine if menorrhagia adversely affects QOL, we surveyed a sample of adolescents in a school setting. As treatment exists for inherited bleeding disorders, it is possible to intervene earlier during adolescence and improve QOL. Our study may have implications for adolescents with menorrhagia; awareness, early diagnosis and knowledge of its effect on the QOL of adolescents may help in the development of intervention and coping strategies.

\section{Methods}

Female students, aged 15-17 years, at an inner city high school in a mid-western US town participated in the study. Appendix 1 contains the survey questionnaire that was administered to the participants. Consent was obtained from the parents and assent from the participants. The survey was designed by 
modifying questions used in adult surveys $[3,6,10]$ because there was no pre-existing QOL questionnaire for adolescents with menstrual problems at the time this survey was undertaken.

The study participants answered questions about their menstrual history. Using the Pictorial Blood Assessment Chart (PBAC) [15], participants estimated the amount of blood loss, which was then converted into a numerical score for the purpose of empirical analysis. A PBAC score of $\geq 100$ was used as an indicator of menorrhagia [15]. The survey instrument also included questions regarding the participants' perceptions about their QOL, a review of symptoms and family history of bleeding problems. Questions on QOL were aimed at assessing the effect of menorrhagia on participation in sports, sleepovers, extra-curricular activities, travel, school absenteeism and feelings of tiredness. The study and the survey instrument were approved by the Michigan State University Investigational Review Board and the School District board. The questionnaire was distributed to a random sample of adolescent girls by the school nurse or a teacher during a specific school hour and collected from the respondents at end of the hour.

All the statistical analyses were conducted using SPss (version 15 for Windows). The analyses primarily focused on differences between the group of participants who had a PBAC score $\geq 100$ (labelled as menorrhagia group) and the group of participants with a PBAC score $<100$. A $Z$-test of difference in proportions was used to examine statistically significant differences between the two groups. The relationship between PBAC and each survey question was quantitatively analysed using a linear regression model, with the survey question as the dependent variable, and PBAC score as the independent. To determine correlations among the QOL questions, a confirmatory factor analysis was obtained. Factor analysis is a statistical technique that uses the associations between variables and clusters them into a smaller number of constructs. A sample size of six observations per variable is likely to be adequate to obtain statistically valid results [16].

The factor analysis revealed that the survey questions loaded on three factors. Four questions dealing with QOL loaded on one factor. These included participation in sporting activities, participation in social activities, sleepovers and travel. Both questions relating to the family history (relatives with bleeding disorders, relatives with menorrhagia) loaded on a second factor and school attendance loaded on a separate factor. Finally, we created a single QOL variable using the factor weights for the four questions related to QOL and estimated a linear regression model with the combined QOL variable as the dependent variable and PBAC score as the independent variable. Diagnostic test indicates that our variables did not significantly depart from normality.

All $P$-values reported are two-sided, except when we had a directional prediction, in which case the $P$ values are one-sided.

\section{Results}

A total of 240 survey questionnaires were distributed and 45 responses were received, for a response rate of $19 \%$. Among the samples, $18(40 \%)$ respondents were caucasians, 17 (38\%) were African-Americans, six $(13 \%)$ hispanics, three $(7 \%)$ biracial and one was of an unspecified race. Median age at menarche was 11-12 years. Median duration of the menstrual cycle was 6 days (range 2-10). A total of 25/45 (56\%) of the respondents had a PBAC score $\geq 100$. Table 1 provides demographics and descriptive statistics for the individuals who participated in the survey.

Results of the $Z$-test indicate that out of the 25 respondents who had a PBAC score $\geq 100,22$ respondents $(88 \%)$ indicated that their period was 'heavy' $(P<0.001)$. As against this, $10 / 20(50 \%)$ participants with a PBAC score $<100$ indicated that their periods were 'heavy' $(P<0.99)$. The proportion of respondents who had a PBAC score $\geq 100$, were

Table 1. Descriptive statistics.

\begin{tabular}{ll}
\hline & \\
Description & $\begin{array}{l}\text { No. of respondents } \\
(\% \text { of total), } n=45\end{array}$ \\
\hline Demography & $18(40 \%)$ \\
Caucasian & $17(38 \%)$ \\
African-American & $6(13 \%)$ \\
Hispanic & $3(07 \%)$ \\
Biracial & $1(02 \%)$ \\
Unspecified & \\
Details of menstrual history: & $11-12$ years \\
Median age at menarche & $($ range $9-15)$ \\
Median duration of menstrual cycle & 6 days \\
Respondents with PBAC score $\geq 100$ & $($ range $2-10)$ \\
Respondents with PBAC score $<100$ & $25(56 \%)$ \\
Respondents who perceived their & $20(44 \%)$ \\
period as heavy & $32 / 45(71 \%)$ \\
Had PBAC score $\geq 100$ & \\
Had PBAC score $<100$ & $22 / 25(88 \%)$ \\
Respondents who perceived their & $10 / 20(50 \%)$ \\
period as 'not heavy' & $13 / 45(29 \%)$ \\
Had PBAC score $\geq 100$ & \\
Had PBAC score $<100$ & $3 / 25(12 \%)$ \\
\hline &
\end{tabular}




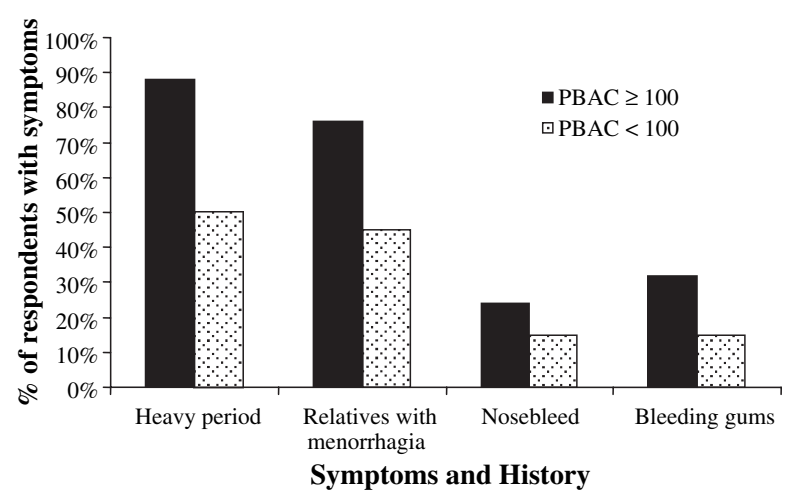

Fig. 1. Pictorial Blood Assessment Chart score, symptoms and family history.

significantly more likely to perceive their periods as heavy compared with the respondents who had a PBAC score $<100(P<0.05)$.

Among the participants with PBAC score $\geq 100$, $19 / 25(76 \%)$ had relatives with menorrhagia, compared with nine of $20(45 \%)$ of the participants who had PBAC score $<100$. This is marginally significant $(P<0.07)$. These relatives were either their mother or a maternal aunt. A history of nosebleed was present in $5 / 25(24 \%)$ of the participants with a PBAC score $\geq 100$ compared with $3 / 20$ $(15 \%)$ participants with a PBAC score $<100$, but this was not statistically different $(P<0.50)$. Similarly, there was no statistical difference in the occurrence of bleeding gums between the participants who had a score of $\geq 100$ PBAC $(32 \%)$ vs. those who scored $<100(15 \%) \quad(P<0.35)$. These results are represented in Fig. 1.

\section{Association of PBAC score with perceptions of quality of life}

Thirteen out of 25 (52\%) individuals with a PBAC score $\geq 100$ missed school during their menstrual periods compared with 4/20 (20\%) individuals with a PBAC score of $<100 \quad(P<0.07)$. Travel was curtailed among $7 / 25(28 \%)$ of the participants with PBAC score $\geq 100$ as opposed to $4 / 20(20 \%)$ of the participants with PBAC score $<100$, as were sleepovers $[8 / 25(32 \%)$ vs. $4 / 20(20 \%)]$ and social activities $[11 / 25(44 \%)$ vs. $7 / 20(35 \%)]$. However, these were not statistically significantly associated with PBAC score. The data is summarized in Fig. 2.

The results of the linear regression model using the combined QOL variable based on factor analyses as the dependent variable and the PBAC score as the independent variable indicated that PBAC score was associated with QOL in a statistically significant manner, that is, the higher the PBAC score, the

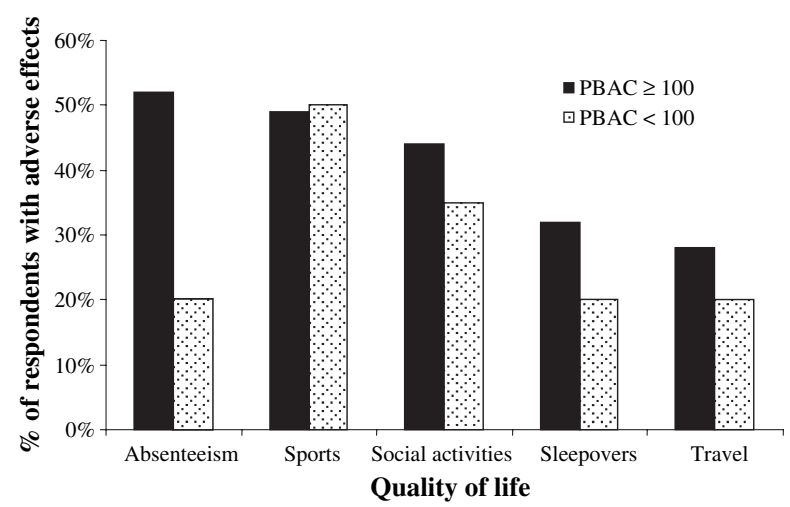

Fig. 2. Score and quality of life.

greater was the likelihood that the individual's QOL was adversely affected $(P<0.025$, one-tailed).

\section{Discussion and conclusions}

This study, conducted in an inner city school indicates that menorrhagia may have a negative influence on QOL, and adolescents with menorrhagia (as evidenced by a higher PBAC score) were marginally more likely to miss school, compared with their peers who did not have menorrhagia.

Philip et al. [14] reported a higher frequency of family history of bleeding disorder among the adolescents with menorrhagia compared to older women. In our study, participants with higher PBAC scores had more relatives with menorrhagia than those with lower PBAC scores. We sent letters to the families of the participants with PBAC score $\geq 100$, offering free testing for bleeding disorders. To date, only one African-American student with a high PBAC score was seen in the clinic. She was diagnosed with a platelet function disorder and is being followed in the Hemophilia Comprehensive Care Clinic.

Despite school curricula regarding education about the normal menstrual cycle during elementary, middle and high school, $12 \%$ of the participants who had a PBAC score $\geq 100$ were not aware that heavy menstrual periods were affecting their QOL. Given the significant prevalence of menorrhagia in the female menstruating population [2] it is important to educate adolescents about abnormal menstrual periods and seek medical intervention as necessary.

A major limitation of our study was the low response rate to the surveys. Another limitation was that the pads and the tampons used by the participants were not standardized for absorbency. Furthermore, we relied on PBAC as an indicator of menorrhagia; some studies have demonstrated a 
poor correlation between PBAC and menstrual blood loss [17]. To eliminate researcher bias, a third party such as the school nurse or teachers administered the questionnaire. As the survey was rendered in a school setting, at the request of the school board, questions about the teenagers' sexual practices were not included in the questionnaire.

Despite its limitations, this is a notable study of adolescents in an inner city high school setting with mixed racial population. The existence of a positive family history of relatives with menorrhagia in these adolescents warrants further testing for inherited bleeding disorders. Haemostatic therapies for underlying bleeding disorders causing menorrhagia [18] may, improve the QOL of affected adolescents. The number of participants who missed school is especially concerning even in our small sample of 45 adolescents. Absenteeism has an impact on academic achievement since adolescents who miss school are more likely to have poorer grades, lower standardized test scores and high-school graduation rates $[19,20]$. In addition, early identification of adolescents with menorrhagia and providing appropriate treatment may prevent unnecessary gynaecological procedures during their adult life. Early diagnosis and intervention with therapeutic and educational strategies may improve QOL. Our study has implications for adolescents with bleeding disorders; increased awareness and education regarding normal and excessive menstrual blood loss may be helpful to both school authorities as well as the student in identifying those at risk. Adolescents with family members with menorrhagia may not perceive their periods as heavy. Perception of menorrhagia in adolescents is variable and may not correlate with actual PBAC score.

Future research on the effect of menorrhagia, including the influence of race, nutritional status (including iron deficiency, obesity), socio-economic status and education in this age group is warranted.

\section{Disclosures}

The authors stated that they had no interests which might be perceived as posing a conflict or bias.

\section{References}

1 Warner P, Critchley H, Lumsden M, Campbell-Brown M, Douglas A, Murray G. Hemorrhagic I: measured blood loss, clinical features, and outcome in women with heavy periods: a survey with follow-up data. Am J Obstet Gynecol 2004; 190: 1216-23.
2 James AH, Ragni MV, Picozzi VJ. Bleeding disorders in premenopausal women: (another) public health crisis for hematology? Hematology 2006; 1: 474-85.

3 Bevan JA, Maloney KW, Hillery CA, Gill JC, Montgomery RR, Scott JP. Bleeding disorders: a common cause of menorrhagia in adolescents. J Pediatr 2001; 138: 856-61.

4 Kirtava A, Crudder S, Dilley A, Lally C, Evatt B. Trends in clinical management of women with von Willebrand disease: a survey of 75 women enrolled in haemophilia treatment centers in the United States. Haemophilia 2004; 10: 158-61.

5 Smith YR, Quint EH, Hertzberg RB. Menorrhagia in adolescents requiring hospitalization. J Pediatr Adolesc Gynecol 1998; 11: 13-5.

6 Kouides PA, Phatak PD, Burkart P et al. Gynaecological and obstetrical morbidity in women with type I von Willebrand disease: results of a patient survey. Haemophilia 2000; 6: 643-64.

7 Chi C, Shiltagh N, Kingman CEC, Economides DL, Lee CA, Kadir RA. Identification and management of women with inherited bleeding disorders: a survey of obstetricians and gynecologists in United Kingdom. Hemophilia 2006; 12: 405-12.

8 Bevan JA, Maloney KW, Hillery CA, Gill JC, Montgomery RR, Scott JP. Bleeding disorders: a common cause of menorrhagia in adolescents. J Pediatr 2001; 138: 856-61.

9 Edlund M, Blomback M, von Schoultz B, Andersson O. On the value of menorrhagia as a predictor for coagulation disorders. Am J Hematol 1996; 53: 234-8.

10 Kadir RA, Sabin CA, Pollard D, Lee CA, Economides DL. Quality of life during menstruation in patients with inherited bleeding disorders. Haemophilia 1998; 4: 836-41.

11 Ruta DA, Garratt AM, Russell IT. Patient centered assessment of quality of life for patients with four common conditions. Qual Health Care 1999; 8: 22-9.

12 Shaw RW, Brickley MR, Evans L, Edwards MJ. Perceptions of women on the impact of menorrhagia on their health using multiattribute utility assessment. $\mathrm{Br} J$ Obstet Gynecol 1998; 105: 1155-9.

13 Philipp CS, Faiz A, Dowling $\mathrm{N}$ et al. Age and the prevalence of bleeding disorders in women with menorrhagia. Obstet Gynecol 2005; 105: 61-6.

14 Jayasinghe $\mathrm{Y}$, Moore P, Donath S, Campbell J, Monagle P, Grover S. Bleeding disorders in teenagers presenting with menorrhagia. Aust N Z J Obstet Gynecol 2005; 45: 439-43.

15 Higham JM, O’Brien PMS, Shaw RW. Assessment of menstrual blood loss using a pictorial chart. $\mathrm{Br} \mathrm{J} \mathrm{Ob}$ stet Gynecol 1990; 97: 734-9.

16 Velicer WF, Fava JL. Effects of variable and subject sampling on factor pattern recovery. Psychol Methods 1998; 3: 231-51.

17 Friberg B, Orno AK, Lindgren A, Lethagen S. Bleeding disorders among young women: a population based 
prevalence study. Acta Obstricia et Gynecologia 2006; 85: 200-6.

18 Demers C, Derzko C, David M, Douglas J, Society of Obstetricians and Gynecologists of Canada. Gynecological and obstetric management of women with inherited bleeding disorders. Int J Gynecol Obstet 2006; 95: 75-87.
19 Galloway D. Schools and Persistent Absentees. Oxford: Pergamon Press, 1985.

20 Jencks C, Phillips M. Aptitude or achievement: why do test scores predict educational achievement and earnings? In: Mayer SE, Peterson PE, eds. Earning and Learning. Washington, DC: Brookings Institute Press, 1999: 15-47. 